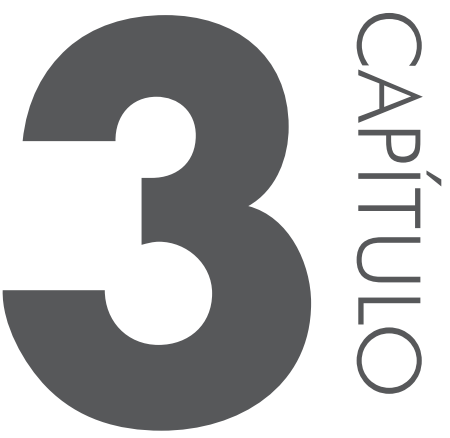

\title{
ENSINO DE HISTÓRIA A PARTIR DO TEATRO: ENTRE PRÁTICAS E REPRESENTAÇÕES
}

Maria Helena Gondim Almeida ${ }^{1}$

Resumo: O que justifica a presente proposta de pesquisa, ainda em desenvolvimento no Programa de Mestrado Profissional em História da Universidade Federal de Goiás/Regional Catalão, é pensar o teatro como possibilidade para trabalhar temáticas históricas propostas nos currículos escolares, abordando os temas de forma interessante, produtiva e prazerosa. O objetivo é explorar a capacidade criativa dos alunos e professores, que podem partir de uma perspectiva interdisciplinar para a produção do conhecimento no ensino de História.

Palavras-chave: ensino de história; teatro; representações; práticas.

1 Unidade Acadêmica Especial de História e Ciências Sociais, Universidade Federal de Goiás/Regional Catalão, Catalão - GO, Brasil

E-mail de contato: leninhagondimalmeida@gmail.com 
Abstract: What justifies this proposed research development in the Professional Master's Program in UFG-RC history is to think of theater as a possibility to work proposed themes in school curricula to address the issues in an interesting, productive and enjoyable way. The aim is to explore the creative ability of students and teachers, who can make use of interdisciplinarity to the production of knowledge in teaching history.

Keywords: history teaching; theater; representations; practices

\section{INTRODUC̣ÃO}

O presente texto tem como objetivo apresentar algumas reflexões, ainda que embrionárias, sobre as discussões propostas pelo projeto de mestrado desenvolvido na Universidade Federal de Goiás/Regional Catalão , pelo PPGH - Mestrado Profissional.

\subsection{Uma conversa inicial}

Ao iniciar minha carreira como docente no ensino fundamental na rede pública municipal da cidade de Uberlândia - MG, em 1992, sempre me encantei por atividades criativas que envolviam práticas de ensino utilizando o teatro como possibilidade metodológica, a partir de um conteúdo de História, recurso que tinha por objetivo fundamental construir novos caminhos de comunicação com os alunos.

O teatro, como recurso metodológico, ensina os alunos a viver e a ampliar seus horizontes culturais, bem como perder a timidez e se colocar no lugar do outro, tornando-se, com isso, um artefato eficaz para o desenvolvimento da capacidade cognitiva, uma vez que, desperta nos alunos o interesse por temas, textos e autores variados.

O uso do teatro como prática metodológica ajuda a desenvolver no aluno a noção de trabalho em grupo e a capacidade de resolver melhor situações que exigem improviso. De acordo com Koudela (1990), consultora do Ministério da Educação na elaboração dos Parâmetros Curriculares Nacionais (PCNs), "o teatro é um exercício de cidadania, um meio de ampliar o repertório cultural de qualquer estudante" (ARAÚJO, 2004, s.p.), enfatizando, assim, as inúmeras habilidades desenvolvidas com essa prática.

Acreditando no uso do teatro como recurso metodológico na prática de ensino, de forma que o desenvolvimento desta pesquisa junto ao Programa de Mestrado Profissional em História UFG/CAC pauta-se na possibilidade de produzir conhecimentos que contribuirão para a reflexão e promoção dos saberes e das práticas de ensino de História. É importante ressaltar que nós, professores de 
História, temos um papel fundamental na formação da consciência histórica dos alunos através da ampliação da relação ensino-aprendizagem, e da incorporação de diferentes linguagens no processo educativo. Diante disso, acreditamos que o teatro constitui um recurso metodológico eficaz para alcançar tais objetivos no que concerne o ensino e a aprendizagem.

Com a publicação da Lei de Diretrizes e Bases da Educação Nacional (BRASIL, 1996, p. 1-2), a arte foi reconhecida como área de conhecimento no currículo escolar. Com a aplicação da referida lei, o teatro alcançou um espaço dentro das escolas como linguagem artística, sugerida pelos PCNs, a ser trabalhado na disciplina de Arte. Mas outras disciplinas, principalmente História, abraçaram a possibilidade do uso do teatro, tendo como perspectiva conteúdos relacionados aos processos históricos. Mesmo com pouquíssimo espaço para discussões, reflexões metodológicas e práticas criativas de ensino em sala de aula, não houve desistência por parte dos professores envolvidos, no sentido de avanço na discussão sobre o uso de linguagens artísticas no ensino de História, principalmente sobre o trabalho com o teatro.

Há algum tempo, novas correntes historiográficas, especialmente do campo da nova história cultural, muito têm contribuído para que os professores pensem conceitualmente a sua prática educativa, e mesmo não conseguindo, ainda, avançar na sua concepção metodológica e prática pedagógica devido a implicações e limitações na formação dos professores, tentam descobrir os fios, tecer a trama e traduzir o mundo a partir da cultura. A História trabalha com a mudança no tempo, e a história cultural assinala a reinvenção do passado através das práticas e representações de mundo partilhadas pelos sujeitos históricos. Para D’Assunção (2011),

“representação”, no campo da História e das Ciências Humanas, é uma palavra com múltiplos significados. As "práticas” se referem aos fazeres, aos modos de agir, as "representações" dizem respeito aos modos de ver e conceber o mundo através de imagens, de esquemas mentais. Assim, há um entrelaçamento entre o fazer e o conceber, ou seja, há uma arquitetura entre “práticas” e "representações” (D’ASSUNÇÃO, 2011, p. 12).

Na nova história cultural, os objetos historiográficos, bem como os temas de abordagem, têm se expandido de forma significativa, o que viabiliza os mais variados estudos sobre a cultura popular, a cultura letrada e as representações sociais, dentre outros. Os historiadores contemporâneos defendem que todos os seres humanos produzem cultura porque "se comunicam por meio dos gestos, do corpo e da sua maneira de estar no mundo social, isso é, do seu 'modo de vida'" (D’ASSUNÇÃO, 2011, p. 13).

A despeito da contribuição de vários autores para a história cultural, D’Assunção cita Roger Chartier, um dos mais conhecidos historiadores da atualidade. Sua 
especialidade é a pesquisa sobre leitura, com ênfase nas práticas culturais da humanidade desenvolvidas em torno do ato de ler, seus objetos e fazeres. Desse modo, o autor afirma que constituem

[...] práticas culturais não apenas a feitura de um livro, uma técnica artística ou uma modalidade de ensino, mas também os modos como, em uma dada sociedade, os homens falam e se calam, comem e bebem, sentam-se e andam, conversam ou discutem, solidarizam-se, morrem ou adoecem, tratam seus loucos ou recebem os estrangeiros (D’ASSUNÇÃO, 2011, p. 17).

Com isso, pode-se situar a pesquisa aqui exposta dentro do referencial teórico da história cultural, pois é ela que instrumentaliza a interpretação da história necessária ao trabalho proposto.

\section{OBJETIVO}

Na perspectiva de que todos os homens produzem cultura e estão inseridos das mais diferentes formas nos processos históricos, é importante que o professor, dentro do espaço escolar, apresente questões que tenham como objetivo problematizar as relações cotidianas que são construídas e vivenciadas pelos alunos. Partimos do pressuposto de que o interesse pelo estudo de História, de uma forma participativa e prazerosa, pode ser despertado a partir do momento em que o professor conscientiza o aluno de que ele se insere como sujeito nos processos históricos e como construtor da cultura que o circunda.

Nesse sentido, propomos tomar o teatro como fonte, como linguagem, mas principalmente como metodologia de ensino de História. Isso porque esta é uma pesquisa que tem como principais objetivos compreender a contribuição do teatro para o ensino de História e identificar se os estudantes são incentivados pelos professores a criar suas próprias encenações ou encenam espetáculos prontos. Ou seja, tem-se os objetivos de tentar entender como o teatro tem sido usado nas escolas e como tem servido ao próprio processo de ensino-aprendizagem. Ainda, investigar o conhecimento técnico dos professores sobre teatro e, também, verificar se há apoio da direção da escola e supervisão pedagógica, no sentido de dar suporte aos professores e alunos no desenvolvimento e montagem de uma peça no espaço escolar.

Tencionamos, por fim, comparar como outras escolas estão envolvidas em projetos teatrais e investigar o porquê da falta da disciplina de Teatro no currículo escolar. Ainda nesta perspectiva, pretendo relacionar e refletir sobre o papel da história, da memória e do teatro no processo de construção de conhecimentos dos professores e estudantes acerca da realidade em que vivem; apresentar o diagnóstico da pesquisa; e elaborar uma metodologia para o uso do teatro no ensino de 
História numa perspectiva interdisciplinar. Esses objetivos estão alicerçados nas experiências que tenho vivido e que mostram a pertinência do uso do teatro como metodologia de ensino-aprendizagem.

\section{METODOLOGIA}

O meu envolvimento com alunos na atividade teatral nas escolas sempre foi algo de relevância, haja vista que os mesmos muitas vezes encenam peças durante a apresentação de trabalhos em feiras culturais ou mesmo em sala de aula. Já apresentamos algumas produções teatrais, como Caravelas no Novo Mundo (1995), de Antônio Augusto da Costa Faria, abordando os primeiros contatos dos europeus com os índios do Brasil, e fizemos algumas atividades teatraisdurante os estudos sobre a República Velha (1889-1930), período de grande instabilidade política: a difícil situação econômica dos pobres e a insatisfação com o domínio das oligarquias geraram vários movimentos populares. Nesse sentido, buscamos na metodologia do teatro a compreensão das rebeliões deste período: Contestado (SC), 1912; Canudos (BA), 1893; Cangaceiros (CE), 1870-1938; Vacina e Chibata (RJ), 1904 e 1910, respectivamente.

A peça A Lei e o Rei, de Teresa Frota (1998), foi encenada em uma experiência interdisciplinar com professoras de História, Geografia e Artes, contando com a participação, na época, de alunos da $7^{\mathrm{a}}$ e $8^{\mathrm{a}}$ séries da Escola Municipal Prof. Domingos Pimentel de Ulhôa, entre março e novembro de 2001. A atividade envolveu a realização de jogos teatrais para que o aluno pudesse escolher a função que mais lhe interessasse no trabalho, de forma que, motivados, os alunos compareceram às reuniões feitas extra turno na escola e, até mesmo, na casa dos professores, devido às dificuldades encontradas no espaço escolar. As habilidades individuais começaram a aflorar para diferentes setores: alguns alunos se identificaram com as coreografias e outros com personagens específicos da peça. O espetáculo foi apresentado na Escola Prof. Domingos Pimentel de Ulhôa, no Teatro Rondon Pacheco, em Uberlândia, e no Centro de Estudos e Projetos Educacionais Julieta Diniz (CEMEPE).

Houve algumas adaptações, com exclusão de falas e adição de jogos teatrais e coreografias. A Lei e o Rei é uma peça épica e o tema principal é a corrupção política. A comparação entre passado e presente foi evidenciada no cenário e no figurino da peça: o painel do cenário mostra um castelo cujas estruturas de sustentação são os dois prédios do Congresso Nacional em Brasília, relacionando uma forma de governo monárquico com o sistema republicano presidencialista brasileiro atual. Alguns móveis usados na montagem do cenário eram rústicos e, ao mesmo tempo, foram utilizadas também peças contemporâneas. No figurino houve um equilíbrio entre roupas do período imperial brasileiro e traços 
modernos, adaptados em função da limitação de recursos materiais para a confecção do figurino. As coreografias apresentadas no decorrer da peça deram mais graça ao espetáculo, tendo como suporte sonoro músicas do repertório nacional e internacional.

Mesmo diante das dificuldades encontradas, o trabalho teatral com os alunos superou todas as expectativas, não somente dos envolvidos no projeto, mas também de toda a equipe escolar, que se emocionou com a atividade e teceu vários elogios acerca desta.

Outro tema bastante pertinente é o racismo, e este se expressa de múltiplas formas nas escolas, refletindo sobre esta temática, que muitas vezes é trabalhada como um discurso de lamentação. Propusemos a leitura do livro Irmão Negro, de Walcir Carrasco (2008), para um trabalho interdisciplinar entre professoras de História, Artes e Literatura, novamente na Escola Municipal Prof. Domingos Pimentel de Ulhôa, em Uberlândia (MG), no período de setembro a novembro de 2011. O processo envolveu os alunos na leitura e interpretação do livro nas aulas de Literatura; o painel, o roteiro, os ensaios e a encenação foram feitos pelas professoras de História e Artes; e o resultado foi, posteriormente, apresentado na Feira Cultural, a partir do Projeto "A Cor da Cultura" - projeto educativo de valorização da cultura afro-brasileira visando a Lei $n^{\circ}$ 10.639/03, que estabelece a obrigatoriedade do ensino da história e cultura afro-brasileiras e africanas nas escolas públicas e privadas do ensino fundamental e médio -desenvolvido ao longo do ano na escola, com apresentação e exposição dos trabalhos realizados na Feira supracitada.

\section{RESULTADOS}

Os resultados aqui apresentados são parciais, uma vez que o projeto se encontra em andamento. Contudo, podemos salientar que nas escolas públicas, no geral, ainda há uma padronização muito grande do fazer docente, em que os professores são condicionados à utilização dos livros didáticos (muitas vezes o único material de leitura dos estudantes), das provas, das Diretrizes, dos cadernos de exercícios e muitos outros. Acerca do nosso condicionamento, Paulo Freire reflete sobre a importância de "reconhecer que somos seres condicionados, mas não determinados. Reconhecer que a História é tempo de possibilidades e não de determinismo, que o futuro permita-me reiterar, é problemático e não inexorável” (FREIRE, 2003, p. 19).

Essa afirmação nos desperta a necessidade de contrapor a realidade em que tudo parece estar já determinado, e vemos o uso do teatro no ambiente escolar como uma ferramenta oportuna para que tais "determinismos" se rompam. Por isso, escolhemos trabalhar com esse outro recurso metodológico que pode 
desenvolver nos alunos uma compreensão crítica do conhecimento histórico, como também sua autonomia na construção e reconhecimento da realidade que os circunda, seja na esfera social, econômica ou política, e refletir sobre isso.

Dessa forma, a linguagem teatral é também um mergulho na história, já que se apropria do discurso histórico e possibilita, por vezes, que encontremos formas e autonomia para interpretar a realidade histórica passada e presente, visando leituras críticas do passado e quiçá, a modificação do presente.

Nessa perspectiva, nossos objetivos, nos trabalhos teatrais com temáticas históricas aqui citados foram, em parte, alcançados, pois possibilitaram uma discussão de saberes históricos que fizeram sentido aos alunos, visto que, por meio das representações teatrais, estes foram instigados a pesquisar diferentes contextos históricos, aprendendo a sistematizá-los, compará-los e atuar como sujeitos da construção do saber ensinado. Essa busca pelo conhecimento ocasionou, em certo modo, uma aproximação entre os alunos e o passado (presente/passado) e, com isso, uma construção do conhecimento a partir da curiosidade pelo passado.

Observamos que a escolha da metodologia teatral é um dos caminhos para conectar o passado ao presente, porque, com o teatro, os saberes, não podem simplesmente ser transferidos, devendo ser pensados, discutidos, refletidos criticamente junto ao grupo, mesmo porque esse caminho metodológico não possibilita o individualismo, o determinismo. Essa metodologia revelou alunos instigadores e mais respeitosos, proporcionando, inclusive, um entendimento mais claro de sua própria vida, de seu bairro, de sua cidade, de seu país. Ou seja, os conhecimentos produzidos em sala de aula a partir da representação teatral não se limitaram ao ambiente escolar, mas alcançaram a própria vida social dos alunos, transcendendo, com isso, os muros da escola.

O trabalho com o teatro promoveu momentos prazerosos, divertidos, alegres e de integração da turma, mas também revelou conflitos e desânimo devido às circunstâncias pouco adequadas na escola para o desenvolvimento de práticas desafiadoras, como o ensino de História e Teatro.

As seguintes frases foram proferidas pelos alunos durante e depois da apresentação do teatro, e podem revelar um pouco da experiência em sala de aula: "houve um aprendizado bem completo sobre a revolta da vacina no Rio de Janeiro, em 1904"; “ houve total integração do grupo, com a participação de todos os envolvidos"; "queremos ressaltar que todos os integrantes do grupo merecem nota máxima, pois todos participaram muito, foi um trabalho difícil, com seriedade e um pouco de diversão, cheio de sentimentos, tudo misturado, de modo que o trabalho se tornasse rico. Gostaríamos de deixar registrado que demos o nosso melhor, devendo agora a professora apresentar o seu ponto de vista sobre o trabalho". 
O grupo destacou, também, alguns pontos negativos, como gasto financeiro excessivo (R \$ 175,00, fora parte final remontada depois); desgaste físico dos participantes; dificuldades para que todos se encontrassem, pois os pais de alguns alunos participantes do grupo no final do primeiro trabalho (que fracassou) não queriam deixar que todos se reunissem; dificuldades de obtenção de cenário (primeiro trabalho); e dificuldades de obtenção de figurino (primeiro trabalho), dentre outros. Além disso, um dos alunos contribuiu com R \$30,00 e ficou indignado com tal quantia.

A partir das declarações dos alunos e alunas, a recepção do ensino de História utilizando o Teatro foi muito positiva e significativa na construção de novas pontes de conexão com os jovens estudantes. A experiência com o teatro, amparada no processo de aprendizagem dos alunos e a partir do empenho e dedicação no trabalho teatral proposto, pauta-se na declaração de Paulo Freire (2003), que afirma que

O educador democrático não pode negar-se o dever de, na sua prática docente, reforçar a capacidade crítica do educando, sua curiosidade, sua insubmissão. Uma de suas tarefas primordiais é trabalhar com os educandos a rigorosidade metódica com que devem se aproximar dos objetos cognoscíveis (FREIRE, 2003, p. 26).

\section{DISCUSSÃO}

Ao contrário do que se pensa, a relação entre teatro e educação é muito antiga. Ainda na Grécia, o teatro adquiriu uma experiência estética original, de caráter artístico, ligada à própria história grega. Japiassu (2001, p. 20) observa que, “já na antiguidade clássica, filósofos gregos (como Aristóteles e Platão) e romanos (Horácio e Sêneca, por exemplo) produziram escritos nos quais foram tecidas considerações a respeito de aspectos da complexa relação entre teatro e educação". Desde então o teatro constitui um meio de compreensão da realidade em que vivemos. Nas palavras de Garcia (1974), o teatro, no campo educacional, tem a tarefa de alertar os alunos para o exercício da cidadania: "o teatro na escola é capaz de oferecer ao aluno a oportunidade de se exprimir livremente, de criar, de extravasar o manancial de riquezas que tem dentro de si" (GARCIA, 1974, p. 9).

Portanto, através dele o aluno pode criar e desenvolver valores morais, principalmente o respeito às diferenças; integrar-se ao grupo; fazer uso da escrita e da linguagem falada e gestual; desenvolver a expressão corporal; conhecer a si mesmo; e expressar o que pensa do mundo e das pessoas, o que aspira, e o que receia. Sem dúvida nenhuma, o teatro na escola é um exercício de criatividade, tanto por parte do aluno como por parte do professor.

Em diferentes campos de atuação, muito se tem falado na importância do teatro na educação, e vários estudiosos consideram essa arte como uma forma 
humana de expressar a relação do homem com o mundo e com outros homens. Nesse sentido, torna-se necessário estudar e sistematizar aspectos simbólicos, de linguagem e comunicação, com o intuito de buscar respostas sobre o que é o mundo. Segundo Cavassin (2008), o teatro aplicado à educação possui o papel de mobilização de todas as capacidades criadoras e o aprimoramento da relação vital do indivíduo com o mundo contingente. As atividades dramáticas liberam a criatividade e humanizam o indivíduo, pois o aluno é capaz de aplicar e integrar o conhecimento adquirido nas demais disciplinas da escola e, principalmente, em sua vida. Isso significa o desenvolvimento gradativo da área cognitiva e também afetiva do ser humano.

Nas discussões aqui expostas, podemos dialogar com outras áreas do conhecimento, como o próprio teatro enquanto campo do saber, a literatura, a sociologia e a filosofia, o que pode ampliar as possibilidades de se pensar o trabalho do professor de História, não somente no que se refere ao ensino, mas também à pesquisa científica.

Por outro lado, é importante pensar no ensino de História e na possibilidade do uso da linguagem teatral como um caminho, ou seja, uma ferramenta pedagógica que pode ser mais prazerosa para o ensino e a aprendizagem, entendendo que não basta ao aluno ler e confrontar documentos, mas formular hipóteses e visualizar o conhecimento da História como construção, podendo, também, ter a oportunidade de representar a história teatralmente, de forma a expressar sua compreensão e entendimento do conteúdo em relação à sua realidade individual.

Numa perspectiva mais ampla, é importante citar a reflexão de Cavassin (2008), ao apontar que

O Teatro, assim, pode ser a brecha que se abre na nova perspectiva da ciência e ensino-aprendizagem, pois envolve essencialmente o que o soberanismo da lógica clássica e do modelo racional excluía: o ilógico, as possibilidades (o "vir a ser"), a intuição, a intersubjetivação, a criatividade... Enfim, elementos existentes nas relações dessa manifestação artística e que são princípios para a concepção de inteligência na complexidade e vice-versa (CAVASSIN, 2008, p. 48).

Diante do que é colocado pela autora, a linguagem teatral muda os paradigmas da lógica clássica de aprendizagem, pois valoriza, também, a brincadeira, o faz de conta, e até mesmo experiências vividas pelas próprias crianças e adolescentes para que estes desenvolvam sua imaginação criativa. Para isso, é necessário discutir os conteúdos, tornando-os vivos; ensinar a interpretar, criticar, ver, sentir, tocar. É importante perceber que, tocar, sentir o sabor... sabor do saber. [...] No momento em que estamos a criar, 
os nossos poros se abrem à nova aprendizagem. As funções cognitivas superiores - analisar, generalizar, compreender, deduzir, imaginar - estariam, assim, em melhores condições de estruturar as aprendizagens, como diria Vygotsky (MENDONÇA, 2009, p. 207).

Dessa forma, a linguagem teatral é também um mergulho na História, já que se apropria do discurso histórico e possibilita, por vezes, que encontremos formas e autonomia para interpretar a realidade e, quiçá, modificá-la. Nessa perspectiva, o que justifica a atual proposta de pesquisa é pensar o teatro como possibilidade para trabalhar temáticas propostas nos currículos escolares, abordando-as de forma interessante, produtiva e prazerosa, embora o sistema de trabalho pedagógico ainda não contribua para o desenvolvimento das capacidades criativas dos alunos e professores.

Ainda vivemos, no cotidiano escolar, uma realidade em que o espaço se caracteriza por inúmeras limitações e dificuldades que não favorecem o processo de construção de um ambiente criativo. Nesse sentido, podemos potencializar a dimensão lúdica focada no conteúdo possibilitando que alunos e professores desenvolvam seus trabalhos com prazer, e não apenas por obrigação.

Pearce, conforme Pereira (2005), considera a brincadeira como base da inteligência criativa, precisando ser desenvolvida para ser atualizada. Para Huizinga (2008), a criança brinca na mais perfeita seriedade. Uma educação lúdica busca a compreensão do ser humano como um ser em movimento permanente de construção de si mesmo. Pensar o ser humano dessa forma "implica compreendê-lo como um ser em mudança, que possui o potencial de assenhorear-se de si, e não como um ser impotente a ser modelado pela escola e a quem deve ser dito o que fazer" (PEREIRA, 2005, p. 2). Portanto, a ludicidade, o prazer e a brincadeira podem estar associados à aprendizagem, sendo o teatro uma possibilidade de se trabalhar esses três elementos.

Podemos dizer, então, que a tarefa dos professores de História é formar o cidadão, partilhando saberes, contribuindo para o desenvolvimento de uma determinada maneira de ver e compreender o mundo de uma forma crítica. Para isso, segundo Gadamer:

Ninguém pode atualmente eximir-se da reflexividade que caracteriza o espirito moderno. Seria absurdo, daqui por diante, confinar-se na ingenuidade e nos limites tranquilizadores de uma tradição fechada sobre si mesma no momento em que a consciência moderna encontra-se apta a compreender a possibilidade de uma múltipla reatividade de pontos de vista. Também nos habituamos, nesse sentido, a responder aos argumentos que se nos opõem através de uma reflexão em que nos colocamos deliberadamente na perspectiva do outro (GADAMER, 2003, p. 18). 
A verdadeira intenção do conhecimento histórico não é explicar um fenômeno concreto como caso particular de uma regra geral. Seu verdadeiro objetivo vem antes da compreensão de um fenômeno histórico em sua singularidade e unicidade: o que interessa ao conhecimento histórico não é saber como os homens, os povos e os Estados se desenvolvem em geral, mas, ao contrário, como este homem, este povo, este Estado veio a ser o que é; como todas essas coisas puderam acontecer e encontrar-se aí.

Ao utilizar o recurso do teatro no ensino de História, pretendo contribuir para uma melhor aprendizagem dos alunos que, por meio das encenações, poderão observar e confrontar as diferentes culturas ao longo da História, e aprofundar temas trabalhados em sala de aula, contrapondo-se ao ensino passivo onde o aluno acumula e memoriza informações, prática muito comum na educação tradicional. Dessa forma, ao estudar uma determinada sociedade e elaborar uma peça, os alunos aprofundam os estudos, podem compreender hábitos da época, traços culturais marcantes, e se sentir sujeitos históricos ativos e críticos. Tudo isso nos faz pensar que ensinar História não é uma profissão exercida algumas horas por semana e, como dirá Benjamin,

O historiador é aquele que tem a função messiânica de colher, como um jardineiro, as últimas flores da esperança que, embora murchas e já sem perfume, ainda teimam em permanecerem balançando sob o vento dos tempos, ainda tremulam como bandeiras que simbolizaram, que foram o escudo e a heráldica, que marcharam à frente dos exércitos de vencidos de todos os tempos. O historiador é a carpideira que, ao mesmo tempo, chora e louva os mortos, que num gesto de carinho para com os que se foram, os veste de novo para um ato inaugural, os faz novamente vir para o centro da sala, para a frente do cortejo, os faz levantar a fronte e novamente falarem, vociferarem, imprecarem, readquirindo o direito à fala e a dirigem seu próprio enterro, a simularem o controle sobre a versão de sua própria vida, da sua própria memória (ALBUQUERQUE JR, 2009, p. 3-5).

$\mathrm{Na}$ construção desse processo de ser professor e ensinar História, passando pela experiência, é necessário pensar no que Pesavento (2005) aponta ao propor que,

Em termos gerais, pode-se dizer que a proposta da História Cultural seria, pois, decifrar a realidade do passado por meio de suas representações, tentando chegar àquelas formas discursivas e imagéticas pelas quais os homens expressaram a si próprios e o mundo. Torna-se claro que este é um processo complexo, pois o historiador vai tentar a leitura dos códigos de um outro tempo, que podem se mostrar, por vezes, incompreensíveis para ele, dados os filtros que o passado interpõe. Este seria, contudo, o grande desafio para a História Cultural, que implica chegar até um reduto de sensibilidades e de investimento de construção do real que não são os seus do presente, a rigor o historiador lida com uma temporalidade escoada, com o não visto, o não vivido, que só se torna possível acessar através de registros e sinais do passado que chegam até ele (PESAVENTO, 2005, p. 42). 
Na perspectiva da autora, podemos entender que a História é uma construção da experiência do passado, mostrando-nos a possibilidade de seu resgate a partir de qualquer tema ou objeto do nosso cotidiano, sendo que a experiência humana não se manifesta somente nas lutas políticas e de classe, mas, também, nos sentimentos, valores, imagens, ritos, crenças e hábitos, enfim, no resgate dos fios, no tecer da trama de sentidos conferidos ao mundo.

Podemos dizer que, infelizmente, as experiências com o ensino de teatro no currículo escolar ainda não se referem às práticas pedagógicas permanentes nas escolas públicas devido à falta de espaço para ensaios e produção, ao número excessivo de alunos, ao tempo reduzido, à falta de apoio pedagógico e até mesmo à formação de professores vinculados aos referenciais artísticos. O que vemos são professores esforçados, inquietos e com sede de trazer o apetite para novos sabores em nossos adolescentes e crianças, trazendo o teatro para as disciplinas como recurso facilitador da aprendizagem.

Nas palavras de Pupo (apud DESGRANGES, 2006), são raros, ainda, esses sabores:

Embora possamos acompanhar experiências bastante fecundas de ensino de Teatro na educação básica, elas tendem a se constituir - com raras e honrosas exceções nas quais se inserem efetivamente dentro de projetos pedagógicos mais amplos - em casos esparsos dentro de modalidades extracurriculares (PUPO apud DESGRANGES, 2006, p. 15-16).

Na perspectiva dos autores, é de muito valor essas experiências que, de certa forma, rompem com as quatro paredes das salas de aula, devendo-se entender que a escola tem uma função central no que se refere à reflexão sobre a importância de projetos e processos que podem potencializar a aprendizagem das jovens gerações de uma forma democrática, participativa e provocativa.

\section{CONCLUSÕES}

Como exposto, a pesquisa ainda está em andamento. No momento, estamos realizando o levantamento bibliográfico e a leitura dos textos do referencial teórico sobre teatro e ensino de História. No entanto, percebe-se a pertinência do uso do teatro como metodologia para o ensino de História, haja vista, como mostrado, as experiências positivas que subsidiaram a elaboração da pesquisa e a proposição de atividades práticas como resultado aplicável de nosso trabalho dentro do Programa de Pós-Graduação em História - Mestrado Profissional.

O processo de orientação irá definir os caminhos metodológicos para a reflexão acadêmica, obtendo conhecimento e argumentação teórica com o objetivo de desenvolver adequadamente as práticas pedagógicas no âmbito escolar. Vale 
lembrar a afirmação de ALBUQUERQUE Jr. (2009, p. 21): “aprendizes de historiador têm que enfiar a mão na massa, têm que praticar cada etapa do ofício, sob pena de nada aprender".

\section{REFERÊNCIAS}

ALBUQUERQUE Jr., D. M. O tecelão dos tempos: o historiador como artesão das temporalidades. Revista Eletrônica Boletim do Tempo, Rio de Janeiro, ano 4, n. 19, 2009. ALMEIDA, M. H. G; LACERDA, G. C.; MONTES, S. R. teatro na escola: uma experiência Interdisciplinar. Cadernos de História, Uberlândia, v. 01, n. 10, p. 51-65, mar. 1990.

ARAÚJO, P. O teatro ensina a viver: a turma perde a timidez, amplia os horizontes culturais e trabalha bem em grupo quando a arte cênica faz parte do currículo. Revista Nova Escola, São Paulo, mar. 2004. Disponível em: <http://revistaescola.abril.com.br/arte/ pratica-pedagogica/teatro-ensina-viver-424918.shtml>. Acesso em: 28 set. 2015.

BRASIL. Lei no 9.394, de 20 de dezembro de 1996. Lei de Diretrizes e Bases da Educação Nacional, Brasília, D.F. Disponível em: <http://www2.senado.leg.br/bdsf/bitstream/ handle/id/70320/65.pdf -2005>. Acesso em: 30 out. 2015.

CARRASCO, W. Irmão Negro. 2. ed. São Paulo: Editora Moderna, 2008.

CAVASSIN, J. Perspectivas para o teatro na educação como conhecimento e prática pedagógica. Revista Cientifica/FAP, Curitiba, v. 3, p. 39-52, jan./dez. 2008.

D’ASSUNÇÃO, J. B. Representações e práticas sociais: rediscutindo o diálogo das duas noções no âmbito da História Cultural Francesa. In: SANTOS, R. M. dos; BORGES, V. R. (Org.). Imaginário e representações: entre fios, meados e alinhavos. Uberlândia: Asppectus, 2011.

DESGRANGES, F. Pedagogia do teatro: provocação e dialogismo. São Paulo: Editora Hucitec: Edições Mandacaru, 2006.

FARIA, A. A. da C. Caravelas do Novo Mundo. São Paulo: Ática, 1995.

FREIRE, P. Pedagogia da autonomia: saberes necessários à prática educativa. São Paulo: Paz e Terra, 1996.

FROTA, T. A Lei e o Rei. In: Coleção Teatro Brasileiro. v. 2. Belo Horizonte: Editora Handam, 1998.

GADAMER, H. Problemas epistemológicos das ciências humanas. In: . O problema da consciência histórica. 2 ed., Rio de Janeiro: Editora FGV, 2003.

GARCIA, E. C. Apresentação. In: ARAÚJO, H. C. de. Educação através do teatro. Rio de Janeiro: Editex, 1974.

HUIZINGA, J. Homo ludens. São Paulo: Perspectiva, 2008.

JAPIASSU, R. Metodologia do ensino do Teatro. Campinas: Papiros. 2001.

KOUDELLA, I. D. Jogos teatrais. São Paulo: Perspectiva, 1990.

MENDONÇA, C. S. Fome de quê? Processos de criação teatral na rede pública de ensino de Salvador. 2009. 238 f. Tese (Curso de Artes Cênicas, Artes Cênicas) Universidade Federal da Bahia-Escola de Teatro, Salvador, 2009. 
PEREIRA, L. H. P. Ludicidade e auto expressão. In:__ Bioexpressão: a caminho de uma educação lúdica para a formação de educadores. 2005. 405 fls. ese (Doutorado em Educação) - Universidade Federal da Bahia, Salvador, 2005. p. 88-141.

PESAVENTO, S. J. História e história cultural. 2. ed. Belo Horizonte: Autêntica, 2005.

VASCONCELOS, C. P. O teatro como linguagem e fonte no ensino de história. In: XXVI Simpósio Nacional de História, 2011, São Paulo. Anais... São Paulo, 2011, p. 1-11. Disponível em: <http://www.snh2011.anpuh.org/resources/anais/14/1300851800_ ARQUIVO_TextoANPUH2011.pdf>. Acesso em: 30 out. 2015. 